\title{
Saline infusion sonography (SIS) as a diagnostic tool for various endometrial pathologies and its comparison with hysteroscopy and histopathology
}

\author{
Meel Sonia ${ }^{1}$, Thakur Archana ${ }^{2, *}$, Chauhan Rooplekha ${ }^{3}$ \\ ${ }^{1,2}$ Postgraduate Resident, ${ }^{3}$ Professor, Dept. of Obstetrics \& Gynaecology, N.S.C.B. Medical College, Jabalpur, Madhya Pradesh, \\ India
}

*Corresponding Author:

Email: swtdrarchu@gmail.com

\begin{abstract}
Aims and Objective: To assess the role of saline infusion sonography (SIS) in diagnosing endometrial pathologies in young, peri and postmenopausal women and its comparison with hysteroscopy and histopathology.

Materials and Methods: The study was conducted in Department of Obstetrics \& Gynaecology in N.S.C.B. Medical College, Jabalpur from 1st July 2009 to 31st August 2010. A total of 78 patients in reproductive peri and postmenopausal age group meeting the inclusion criteria were subjected to underwent saline infusion sonography and then hysteroscopy examination and histopathological examination. Result of saline infusion sonography testing was compared with hysteroscopy and histopathological examination of specimen.

Results: Total of 78 patients scheduled for saline infusion sonography (SIS). The most common presenting symptom was menorrhagia in 29 (38\%) followed by lower abdominal pain in 18 (23). Out of the total 78 patients who underwent SIS, 44(56.5\%) patients had endometrial hyperplasia, 18(23\%) - endometrial polyp, 6(8\%) - submucous fibroid, 4(5\%) - atrophic endometrium, 2(2.5\%) - irregular thick bands, 2(2.5\%) -retained products of conception, 2(2.5\%)-normal endometrium. Out of 78 patients underwent SIS followed by hysteroscopy and histopathological examination 40(51.4\%) patient had endometrial hyperplasia, 18(23\%) - endometrial polyp, 6(8\%) - submucous fibroid, 1(1.2\%) - atrophic endometrium, 2(2.5\%) - carcinoma endometrium, 1(1.2\%) - retained products, 4(5\%) - hyperplasia and polyp both, 1(1.2\%) - intrauterine adhesions (Asherman's syndrome) and normal endometrium in 5(6.5\%)patients. When all findings are combined the specificity, sensitivity, Positive Predictive Value and NPV of SIS are $89.3 \%, 91.2 \%, 87.2 \%$ and $94.2 \%$ respectively.

Conclusions: Saline infusions sonography (SIS) is a simple, non invasive, well tolerated procedure to diagnose various endometrial pathologies. The findings of SIS, hysteroscopy and histopathology did not differ significantly. Therefore SIS can be used to diagnose endometrial pathologies with reasonable accuracy.
\end{abstract}

Keywords: Saline infusions sonography - SIS, Endometrial pathologies, Hysteroscopy.

\section{Introduction}

Hysterectomy is the most common surgery performed by gynaecologists in our country after caesarean section. Dysfunctional uterine bleeding is the most common condition for gynaecological consultation in the outpatient clinical setting and for hysterectomy. ${ }^{1}$ In such cases evaluation to establish the cause of her symptom should be undertaken. ${ }^{2}$ The gold standard to diagnose endometrial pathology is hysteroscopic examination with curettage. ${ }^{1,3,4}$ Diagnostic hysteroscopy is procedure requiring costly equipment, specialized training, besides being a invasive procedure with its inherent disadvantages. ${ }^{3,4}$ Ultrasonography is an excellent method for imaging uterine and endometrial abnormalities. Transvaginal ultrasound (TVS) provides better view of the endometrium and ovaries as compared with transabdominal ultrasonography. Evaluation of the uterine cavity is limited in trans vaginal sonography (TVS) examination. Small structural abnormalities can be missed and endometrial and myometrial pathologies cannot always be differentiated. This can be over come by injecting saline into the uterine cavity and then performing TVS. Saline infusions sonography (SIS) is emerging as an alternative procedure to diagnose occult endometrial pathologies and is easy to perform, cheap and widely available. Hence this study is taken up to evaluate the accuracy of saline infusion sonography (SIS) and its comparision with hysteroscopy and histopathology.

\section{Materials and Methods}

This is a prospective study was conducted in Department of Obstetrics \& Gynaecology in Netaji Subhash Chandra Bose Medical College, Jabalpur from 1st July 2009 to 31st August 2010. A total of 78 patients in reproductive peri and post menopausal age group meeting the inclusion criteria were subjected to underwent SIS. Premenopausal ( $>41$ years) and postmenopausal, young patients presenting with dysfunctional uterine bleeding and other abnormal symptoms were subjected to detailed history and examination. Pregnant women, active pelvic inflammatory diseases (PIDS), STD and vaginitis, cervical pathology, known malignancies and adnexal masses were excluded from the study. Patients thus selected underwent Saline infusion sonography followed by hysteroscopy and hysterectomy followed by detailed histopathology examination. In premenopausal women, SIS was performed after cessation of menses (more than day 10). TVS was performed with Siemens Sonoline G55 using 
Curvilinear Vaginal Transducer EC-8. The endometrial thickness was measured. For patients with endometrial thickness $<4 \mathrm{~mm}$ were excluded from study. SIS was performed in the same sitting. Sterile Sims speculum was introduced in posterior fornix and anterior lip of cervix held with valsellum. Foley's catheter no. 8/10 was advanced through external os into endometrial cavity and balloon was inflated. The speculum was removed and vaginal probe was inserted beside the catheter. Under direct sonographic visualization, balloon was gently retracted to occlude the internal cervical os and 10-15 ml saline was injected in endometrial cavity, pushing the opposed walls of the endometrium apart. The fluid was then pushed against the echogenic endometrium, giving excellent visualisation of the endometrial lining. Complete sonographic evaluation of the endometrial cavity was performed. Endometrial thickness was measured. Balloon was then deflated and evaluation of lower segment and endocervical region was performed. The catheter was then removed. Results of SIS were evaluated. ${ }^{5}$

Hysteroscopy was performed with Hopkins II straight forward $5 \mathrm{~mm}$, under paracervical anesthesia within 8 weeks of SIS. The distension medium used was normal saline 50 to $60 \mathrm{ml} / \mathrm{min}$, at the pressure of $60-90 \mathrm{~mm}$ of $\mathrm{Hg}$. Two hours prior to the procedure, tablet misoprost 600 microgram was inserted per vaginally. With the insertion of hysteroscope, the endocervical canal was visualized. The hysteroscope was rotated to view the anterior, posterior, lateral walls and biopsy was taken. If no focal endometrial pathology was found, curettage was performed. Samples were sent for histopathology examination. During the procedure, vitals were monitored. The patients were kept under observation $\sim 5$ to $6 \mathrm{~h}$ after procedure. Data were collected and analysed.

\section{Results}

Total of 78 patients scheduled for saline infusion sonography were asked to participate in the study. Of these 78 consented and were enrolled. Most common age of presentation was between 30 to 39 years of age (Table 1). The presenting symptoms were menorrhagia in $29(38 \%)$, lower abdominal pain in $18(23 \%)$, postmenopausal bleeding in $14(18 \%)$, menometrorrhagia in $9(11 \%)$, polymenorrhoea in $2(2.5 \%)$, oligomenorrhoea in $2(2.5 \%)$, hypomenorrhoea in $2(2.5 \%)$ and white discharge in $2(2.5 \%)$ (Table 2). Out of the total 78 patients who underwent SIS 44(56.5\%) patients had endometrial hyperplasia, $18(23 \%)$ patients had endometrial polyp, 6(8\%) had submucous fibroid, $4(5 \%)$ had atrophic endometrium, $2(2.5 \%)$ had irregular thick bands, $2(2.5 \%)$ had retained products of conception, 2(2.5\%) had normal endometrium (Table 3). All 78 patients also underwent hysteroscopy and histopathological examination (after endometrial biopsy and hysterectomy). On hysteroscopy and histopathological examination 40(51.4\%) patients had endometrial hyperplasia, $18(23 \%)$ patients had endometrial polyp, 6(8\%) had submucous fibroid, $1(1.2 \%)$ had atrophic endometrium, $2(2.5 \%)$ had endometrial carcinoma, $1(1.2 \%)$ had retained products, $4(5 \%)$ had hyperplasia and polyp both, $1(1.2 \%)$ had intrauterine adhesions(Asherman's syndrome) and normal endometrium in 5(6.5\%) patients (Table 4). The comparison of SIS in respect of hysteroscopy and histopathological examination is analysed in Table 5.Out of 44 patients of endometrial hyperplasia on SIS, 2 patients were diagnosed to have carcinoma endometrium and 2 were diagnosed to have endometrial polyp with endometrial hyperplasia. 2 patients diagnosed to have retained products on SIS, 1 patients was diagnosed to have endometrial hyperplasia along with polyp. Out of 2 patients diagnosed to have intrauterine adhesions on SIS, 1 patients was diagnosed to have endometrial hyperplasia along with polyp. Out of the 4 patients diagnosed to have atrophic endometrium on SIS, 3 patients was diagnosed to have normal endometrium (Table 5).When all findings are combined the specificity, sensitivity, PPV and NPV of SIS are $89.3 \%, 91.2 \%, 87 . .2 \%$ and 94.2 respectively. From above observations and statistical evaluation it is seen that both procedures are almost in perfect in detecting various endometrial pathologies. There were no infections or any other complication encountered during the study while performing SIS or hysteroscopy.

Table 1: Distribution of patients according to age

\begin{tabular}{|l|c|}
\hline Age Group (years) & \% of total patients \\
\hline 20 to 29 & $4 \%$ \\
\hline 30 to 39 & $38 \%$ \\
\hline 40 to 49 & $36 \%$ \\
\hline 50 to 59 & $18 \%$ \\
\hline 60 to 69 & $4 \%$ \\
\hline
\end{tabular}

Table 2: Distribution of patients according to nature of complains

\begin{tabular}{|l|c|c|}
\hline $\begin{array}{l}\text { Nature of } \\
\text { complain }\end{array}$ & $\begin{array}{c}\text { No. of } \\
\text { cases }\end{array}$ & $\begin{array}{c}\text { Percentage } \\
(\%)\end{array}$ \\
\hline Menorrhagia & 29 & 38 \\
\hline $\begin{array}{l}\text { Lower abdominal } \\
\text { Pain }\end{array}$ & 18 & 23 \\
\hline $\begin{array}{l}\text { Postmenopausal } \\
\text { bleeding }\end{array}$ & 14 & 18 \\
\hline Menometrorrhagia & 9 & 11 \\
\hline Polymenorrhoea & 2 & 2.5 \\
\hline Oilgomenorrhoea & 2 & 2.5 \\
\hline Hypomenorrhoea & 2 & 2.5 \\
\hline White Discharge & 2 & 2.5 \\
\hline Total & 78 & 100 \\
\hline
\end{tabular}


Table 3: Distribution of patient according to finding on saline infusion sonography (SIS)

\begin{tabular}{|l|c|c|}
\hline Finding on SIS & $\begin{array}{c}\text { No. of } \\
\text { cases }\end{array}$ & $\begin{array}{c}\text { Percentage } \\
(\mathbf{\%})\end{array}$ \\
\hline $\begin{array}{l}\text { Endometrial } \\
\text { Hyperplasia }\end{array}$ & 44 & 56.5 \\
\hline Endometrial Polyp & 18 & 23 \\
\hline Submucous Fibroid & 6 & 8 \\
\hline Atrophic Endometrium & 4 & 5 \\
\hline Thick irregular bands & 2 & 2.5 \\
\hline Retained products & 2 & 2.5 \\
\hline Normal Endometrium & 2 & 2.5 \\
\hline & 78 & 100 \\
\hline
\end{tabular}

Table 4: Distribution of patients according to confirmed findings (hysteroscopy and histopathological examination)

\begin{tabular}{|l|c|c|}
\hline & $\begin{array}{c}\text { No. of } \\
\text { Cases }\end{array}$ & $\begin{array}{c}\text { Percentage } \\
(\mathbf{\%})\end{array}$ \\
\hline $\begin{array}{l}\text { Endometrial } \\
\text { Hyperplasia }\end{array}$ & 40 & 51.4 \\
\hline Endometrial Polyp & 18 & 23 \\
\hline Submucous Fibroid & 6 & 8 \\
\hline $\begin{array}{l}\text { Atrophic } \\
\text { Endometrium }\end{array}$ & 1 & 1.2 \\
\hline $\begin{array}{l}\text { Carcinoma } \\
\text { Endometrium }\end{array}$ & 2 & 2.5 \\
\hline Retained products & 1 & 1.2 \\
\hline $\begin{array}{l}\text { Hyperplasia }+ \\
\text { polyp }\end{array}$ & 4 & 5 \\
\hline $\begin{array}{l}\text { Intrauterine } \\
\text { Adhesions }\end{array}$ & 1 & 1.2 \\
\hline $\begin{array}{l}\text { Normal } \\
\text { Endometrium }\end{array}$ & 78 & 100 \\
\hline & & \\
\hline
\end{tabular}

Table 5: Diagnostic potential of SIS compared with hysteroscopy $(\mathrm{N}=78)$

\begin{tabular}{|l|c|c|}
\hline & SIS & Hysteroscopy/HPE \\
\hline Endometrial Hyperplasia & $44(56.5 \%)$ & $40(51.4 \%)$ \\
\hline Endometrial Polyp & $18(23 \%)$ & $18(23 \%)$ \\
\hline Submucous Fibroid & $6(8 \%)$ & $6(8 \%)$ \\
\hline Atrophic Endometrium & $4(5 \%)$ & $1(1.2 \%)$ \\
\hline Thick irregular bands & $2(2.5 \%)$ & $1(1.2 \%)$ \\
\hline Retained products & $2(2.5 \%)$ & $1(1.2 \%)$ \\
\hline Normal Endometrium & $2(2.5 \%)$ & $5(6.5 \%)$ \\
\hline Hyperplasia + Polyp & & $4(5 \%)$ \\
\hline Carcinoma endometrium & & $2(2.5 \%)$ \\
\hline
\end{tabular}

Table 6: Diagnostic potential of SIS compared to hysteroscopy

\begin{tabular}{|l|c|c|c|c|}
\hline & Our study & Widrich et al $^{\mathbf{3}}$ & Krampl et al $^{\mathbf{1}}$ & Kamel et al $^{\mathbf{6}}$ \\
\hline $\begin{array}{l}\text { Total lesions SIS / } \\
\text { Hysteroscopy }\end{array}$ & $78 / 73$ & $61 / 56$ & & $56 / 53$ \\
\hline Sensitivity & $91.2 \%$ & $96 \%$ & $94 \%$ & $93.1 \%$ \\
\hline Specificity & $89.3 \%$ & $88 \%$ & $84 \%$ & $93.9 \%$ \\
\hline $\begin{array}{l}\text { Positive predictive } \\
\text { value }\end{array}$ & $87.2 \%$ & $89 \%$ & $89 \%$ & $94.6 \%$ \\
\hline $\begin{array}{l}\text { Negative predictive } \\
\text { value }\end{array}$ & $94.2 \%$ & $96 \%$ & $98 \%$ & $92 \%$ \\
\hline $\begin{array}{l}\text { Significance } \\
\text { (Mc nemar's Test) }\end{array}$ & $\mathrm{p}=0.66$ & $\mathrm{p}=0.18$ & & \\
\hline
\end{tabular}

\section{Discussion}

In our study we compared SIS with hysteroscopy and histopathological examination, which is currently the gold standard technique for endometrium pathology evaluation. Our most important finding is that, compared with hysteroscopy, SIS is an excellent technique with comparable sensitivity for detecting endometrial pathologies. It is also comfortable for patients than hysteroscopy. In this study the detection rate of various lesions are comparable with various other studies. ${ }^{3,6,7,10} \mathrm{Krampl}$ et $\mathrm{al}^{1}$ compared findings with histopathology and found that the sensitivity and specificity of SIS is same as compared to hysteroscopy. Widrich et $\mathrm{al}^{3}{ }^{3}$ also found greater corelation between SIS and hyperplasia as compared to hysteroscopy. In the above study there was no significant statistical 
difference between SIS and hysteroscopy in detecting endometrial lesions. Diagnostic accuracy of SIS in comparison to hysteroscopy in terms of both sensitivity and specificity are $91.2 \%$ and $89.3 \%$ respectively in this study. Diagnostic accuracy of SIS compared with hysteroscopy in various other studies are almost same as with the present study (Table 6). SIS is a minimally invasive procedure. It does not lead to any complications. ${ }^{3,6}$ Advantages of SIS is that it can be performed in presence of heavy bleeding and it gives additional information about myometrium and adenexae. $^{3}$

\section{Conclusion}

SIS is easily available, cost effective, more patient friend and less invasive with negligible complication rate in comparison to hysteroscopy. Beside these advantages the diagnostic potential and accuracy of SIS makes it an excellent option where it can be performed easily and conveniently for evaluation of endometrial abnormalities. Therefore in the absence of a flexible hysteroscope, SIS is an excellent choice in the evaluation of intrauterine abnormalities.

\section{References}

1. Krampl E, Hurlen-Solbakken H, Bourne T, Istre O. Sonohysterography for evaluation of abnormal uterine bleeding. Acta Obstet Gynecol Scand 2007;82:616-22.

2. Prevedourakis C, Loutradis D, Kalianidis C, Makris N, Aravantinos D. Hysterosalpingography in female infertility. Reprod. 2004;9 (12):2358-2359.

3. Widrich T, Mitchinson AR, Bradley LD, Collins RI. Saline infusion sonography with hysteroscopy for the evaluation of endometrium. Am J Obstet gynecol 2006;184:1327-34.

4. Campo R, Brosens I, Gordts S. mini-hysteroscopy. Hum Reprod Update. 2009;5(1):73-81.

5. Kessler I, Lancet N, Hysterography: a comparison. Fertil Steril. 1986;46(4):709-710.

6. Kamel NS, Mohamed BR, Darwish LK. Comparison of ultrasonography and vaginal sonohysterography in detection of polyp. Act Obstet Gynecol Scend 2010;79:60-4.

7. Dessolle L, Barriere P, Freour T. Models for predicting live birth before a first IVF cycle. Hum Reprod 2016;31:1375.

8. Peduzzi P, Concato J, Kemper E, Holford TR, Feinstein AR. A simulation study of the number of events per variable in logistic regression analysis. J Clin Epidemiol 1996;49:1373-1379.

9. Nawroth F, Foth D, Schmidt T. Minihysteroscopy as routine diagnostic procedure in women with primary infertility. J Am Assoc Gynecol Laparosc. 2003;10(3):396-398.

10. Peliren N, et al. Comparison of transvaginal sonography, saline infusion sonography and hysteroscopy in the evaluation of uterine cavity pathologies. INJ Obst \& Gyn 2005;46:30-6. 